Anterior tympanic artery 388

Aponeurosis 48

Argyrophilic nucleolar organizer region 283

Arteries, head 319

Articular cartilage 359

Assisted hatching 220

Basal cells 20

Black and white young men 373

Blastocyst coverings 180

Bone minerals 267

Calcitonin gene-related peptide 249

Capsule 359

Caroticotympanic artery 319

Cat 354

Centriole development 338

Chondrogenesis 6

Ciliogenesis 338

Contraception 233

Cryptorchidism 249

Development 6, 165, 180, 388

Diabetes 31

Differentiation 15

\section{Elbow joint 359}

Embryonic coats 180

Epithelial-mesenchymal interactions 6

- transition 249

Epithelium 20

Equus 304

Ethanol 259

Eutherian mammals 180

Extracellular matrix 148, 233

- - coat 208

Extraocular muscles 330

Fertilization 165

Fetal development 359

Fish 294

Fuchsin, basic 40

Germ layers 6

Glycosylation 148

Granulosa cells 148
Hair cycle 354

- growth 354

Hepatic lobes 378

Hoof function 304

Horse 304

Human 388

- elbow 359

- embryo 15

- fetuses 349

5-Hydroxytryptamine 259

Immunocontraception 228

Implantation 180

Inguinal hernia 249

Innervation 325

Interglobular dentine 40

Internal carotid artery 319

- maxillary artery 388

Intestine 294

Intraepithelial capillaries 349

Intrahepatic ramification 378

Laminae 304

Leptin 15

Lumbosacral ligament 373

Lumbrical muscle 325

Lymphocytes 20

Macrophages, bovine 20

Malocclusion 283

Marsupials 208

Mesenchyme 6

Metaphysis 267

Mouse 6, 31, 259

Mucoid coat 208

Muscle contraction 48

- spindle 325

Muscle-tendon junction 48

Neuromuscular junction 330

Neurulation 6

Oestrous cycle 338

Olfactory mucosa 349

Oophorectomy 267

Opossum 330

Oreochromis niloticus 294

Oviduct 165, 275

Oviductal proteins 233
Phenol block 325

Pig 275

Pituitary 31

Portal vein 378

Preadipocytes 15

Processus vaginalis 249

Proliferating cell nuclear antigen 354

Proteins, secreted 165

Rana pipiens 48

Rat 267, 325

Secondary induction 6

Semitendinosus 48

Sensory neurons 275

Shell 208

Sinus hair follicle 354

Somatotroph 31

Sperm receptor 148

Stapedial artery 388

Strain rate 48

Subsegmental divison 378

Synovial tissue 359

Tail bud 6

- growth 6

Temporal bone structure 319

Tendon mechanics 48

Tilapia 294

Tooth roots, human 40

Ulcer 259

Uterine proteins 233

- tube 20,338

Vertebral column 373

Viscoelasticity 48

Wistar rat 283

Zona drilling 220, 233

- hardening 220

- pellucida 148, 165, 208, 220, 228

- proteins 233

ZP3 228

Zygomaticomaxillary suture 283

\section{KARGER}

(c) 2000 S. Karger AG, Base

Fax + 41613061234

E-Mail karger@karger.ch www.karger.com
Accessible online at www. karger.com/journals/cto 